\title{
Entre a Retórica e a Filologia: do pragmatismo ao humanismo na epistemologia da Ciência da Informação ${ }^{1}$
}

\author{
Between Rhetoric and Philology: from humanism to pragmatism in Information Science \\ epistemology
}

Gustavo Silva Saldanha

Doutorando em Ciência da Informação - IBICT/FACC/UFRJ

Professor Assistente da Escola de Biblioteconomia da Universidade Federal do Estado do Rio de Janeiro, UNIRIO

E-mail: saldanhaquim@gmail.com

\begin{abstract}
Resumo
Identifica e discute a presença do humanismo na epistemologia da Ciência da Informação. Analisa o desenvolvimento contemporâneo do discurso epistemológico informacional e apresenta o pragmatismo, enquanto filosofia e método, como via que conduz o campo à recuperação dos elementos do olhar humanista sobre a realidade. Define a noção de humanismo a partir de um enfoque disciplinar que parte da Filologia e da Retórica. Conclui que o desenvolvimento epistemológico da Ciência da Informação se direciona no horizonte dos métodos de intervenção que se fundamentam entre a Retórica e a Filologia. Aponta as possibilidades teórico-metodológicas de reconhecimento do humanismo na epistemologia informacional.
\end{abstract}

Palavras-chave: Epistemologia da Ciência da Informação - Humanismo - Retórica - Filologia

\begin{abstract}
Discusses the presence of humanism in the epistemology of Information Science. Examines the contemporary development of the pragmatism discourse in information studies. Defines the notion of the humanism and approaches philology and rhetoric as two areas that define the general concept of the traditional humanism. Concludes that the epistemological development of information science is directed at the horizon of the intervention methods that are based between the rhetoric and philology. It points theoretical and methodological possibilities of recognition of humanism in epistemology informational.
\end{abstract}

Key words: Epistemology of Information Science; Humanism; Rhetoric; Philology

\section{Introdução}

As transformações ocorridas e as alternativas trilhadas pela epistemologia da Ciência da Informação na contemporaneidade respondem pelo complexo de deslocamentos de métodos e aplicações nos estudos informacionais. A interpretação destas transformações permite-nos

\footnotetext{
${ }^{1}$ Texto modificado apresentado no GT1 do ENANCIB 2009 em João Pessoa-PB. InCID: R. Ci. Inf. e Doc., Ribeirão Preto, v. 2, n. 1, jan./jun. p. 47-67 , 2011.
} 
compreender as perspectivas do campo, como revisitar, com olhares críticos, a história dos estudos orientados para a organização dos saberes.

No caso da pesquisa brasileira, por exemplo, destaca-se a presença de um grupo de trabalho diretamente voltado para a epistemologia, a partir do ano 2000, no Encontro Nacional de Pesquisa em Ciência da Informação (ENANCIB). Outro exemplo objetivo destas visitas freqüentes à epistemologia do campo está no número de trabalhos que imaginam o espectro das relações interdisciplinares da Ciência da Informação, como também nas pesquisas que procuram interpretar os eventos que dão origem à mesma e reposicionam o conceito que nomeia o campo.

Estas vozes transmitem, no plano geral, a compreensão de uma Ciência da Informação próxima às ciências humanas e sociais, orientada para os estudos sócio-culturais do homem na tessitura de dispositivos de transmissão, representação, mediação e preservação dos saberes. Neste momento, discute-se a noção de informação, que passa a ser encarada também como produto subjetivo de um contexto específico de construção de sentidos. De um modo geral, a Ciência da Informação vivencia uma retomada dos fundamentos humanistas dentro do pensar científico, assim como ocorre com diferentes disciplinas íntimas de seu desenvolvimento.

Aplicado à reflexão epistemológica, o pensamento humanista sobre o conhecimento permite a relativização da noção de ciência enquanto uma sociedade a-política, fechada e segregada da realidade social. A percepção é sustentada fundamentalmente pelas noções e práticas oriundas de duas disciplinas estruturais dos centros de ensino do Renascimento: a Filologia e a Retórica - esta, observada por Capurro (1992) como espaço epistemológico onde a Ciência da Informação se desenvolveria na contemporaneidade. Em diferentes discursos e práticas científicas no âmbito da pesquisa em Ciência da Informação na atualidade percebemos a recuperação dos modelos destas disciplinas. Esta verificação apresenta-nos o seguinte problema, que procuramos aqui refletir: como podemos interpretar e discutir a ascensão dos domínios humanistas dentro da epistemologia da Ciência da Informação, sem desvincular o olhar teórico da prática do pesquisador informacional?

A leitura epistemológica de teorias e propostas metodológicas nos estudos informacionais nos permitirá tecer a compreensão das importantes movimentações do campo, identificando suas premissas em construção, e aprofundando nossa visão historiográfica sobre a amplitude da InCID: R. Ci. Inf. e Doc., Ribeirão Preto, v. 2, n. 1, jan./jun. p. 47-67 , 2011. 
Ciência da Informação no plano da história das ciências. A proposta deste trabalho é apresentar e fomentar a discussão em torno do humanismo na epistemologia da Ciência da Informação, a partir da discussão das questões inerentes à Retórica e à Filologia como macro-disciplinas dispersas nas abordagens e metodologias de pesquisa do campo.

Utilizaremos a adjetivação "pragmatista" para identificar o pragmatismo, como filosofia e método, quando apresentamos no artigo o discurso sob nosso ponto de vista. No entanto, especificamente neste trabalho, abordamos a noção como sinônimo de "pragmático/pragmática", do modo como os autores do campo em geral apresentam esta filosofia, como percebemos em Capurro e Rendón Rojas. Assim, quando a noção aparece na voz dos pesquisadores, conservamos o termo assim como ele é apresentado. Nosso intuito é escapar do significado pejorativo que o termo "pragmático" pode conter no contexto da língua portuguesa, destacando o papel do pragmatismo como relevante reflexão filosófica e metodológica sobre a linguagem.

Os percursos contemporâneos dos estudos informacionais: primeiras impressões

A demanda por pesquisas no âmbito epistemológico tem crescido a cada ano dentro da Ciência da Informação. Diferentes vozes, como aquela de Gomes (2006), têm alertado, ao longo da formação discursiva dos estudos informacionais, sobre a baixa produção do campo em epistemologia. A partir da década de 1990, começamos a perceber um grande foco de produção meta-reflexiva. Trata-se de um conjunto de discursos que volta-se para a discussão do estatuto científico da Ciência da Informação, da conceituação do campo, de sua missão e de seu posicionamento diante de outros ramos de investigação, conjunto representado por trabalhos como aqueles de Rendón Rojas (1996), Loureiro (1999), Freire (2004), González de Gómez (2001), Pinheiro (2005) e Day (2005).

Compreender estas diferentes movimentações é tarefa urgente e fundamental para a produção científica em Ciência da Informação. Tal tarefa responde por outras questões, de ordem política, curricular e social dentro do campo. A retomada dos pressupostos retórico-filológicos remetem, como mencionado, à iluminação do pensamento humanista dentro das academias, e é 
apresentada sob diferentes vocabulários. No âmbito epistemológico, Santos (1987) tratará esta movimentação como "paradigma emergente".

O paradigma do filósofo português Boaventura Santos (1987) teria um cunho especulativo, superando a dicotomia entre ciências naturais e ciências sociais. Para o autor, à medida que as ciências naturais se aproximam das ciências sociais, essas se aproximam das humanidades. $\mathrm{O}$ grande valor das humanidades, discute o pensador, é terem resistido à separação entre sujeito e objeto, preferindo "a compreensão à manipulação do mundo", o diálogo à representação (SANTOS, 1987, p. 43). Esta via filosófica é exatamente aquela adotada pelo pensamento pragmatista, um dos dispositivos teórico-metodológicos que permitem a reaproximação aos domínios humanistas na atualidade.

Como Richard Rorty (1997) aponta, no olhar pragmatista a criação científica apresenta-se como uma outra construção cultural da realidade. É importante notar que o pragmatismo, enquanto filosofia e método, tem profundas incursões na CI (RENDÓN ROJAS, 1996; GONZÁLEZ DE GÓMEZ, 1996). É também de grande relevância observar que os fundamentos do olhar pragmatista sobre o mundo abrem caminho na epistemologia da Ciência da Informação, como ocorre em outros campos, para a aproximação do campo do pensamento humanista e, fundamentalmente, devido às características históricas da esfera informacional, para a exploração da Retórica e da Filologia, vivenciadas, quando tratamos do mesmo âmbito filosófico, por exemplo, no passado, pela Biblioteconomia erudita e pela Bibliografia textual. Esta é a aproximação que podemos observar em enfoques contemporâneos como a Análise do Domínio (HJORLAND; ALBRECHTSEN, 1995), a Antropologia da Informação (MARTELETO, 2002) e a Cibersemiótica (BRIER, 1996).

Para Rendón Rojas (1996), o enfoque pragmático é um fundamento essencial para o estudo da informação, uma vez que reconhece a dialética do sujeito com o mundo que o cerca. González de Gómez (1996) partilha da mesma opinião. A pesquisadora observa que a pragmática apresenta elementos para superar os limites, as simplificações e exclusões das teorias sintática e semântica da informação. Segundo González de Gómez (1996), na década de 1980, diversos estudos da informação se concentraram no problema da relação significado-informação, mas a partir de diferentes objetivos. Dentre estes, dinamizar sistemas de recuperação da informação, 
aperfeiçoar os mecanismos de representação informacional e incorporar a diversidade cultural na programação de ações locais. A afirmação do homem em suas relações sociais como horizonte das investigações no campo - o homem e não a informação como objeto da Ciência da Informação (CAPURRO, 1992) - permite a identificação da hipótese inicial da relação entre o pragmatismo e a discursividade do humanismo no campo informacional.

A velocidade com que a pesquisa no campo se desenvolve e a relevância contemporânea destes deslocamentos, somadas à necessidade permanente de um olhar epistemológico profundo sobre nossos discursos e nossas práticas, chamam a atenção para o olhar abrangente sobre a Ciência da Informação no universo científico atual. Do mesmo modo, tais questões atestam a emergência de uma análise dos caminhos que levaram o campo até este momento teórico, como também a urgência do estudo dos horizontes que tais evidências anunciam.

Em outras palavras, esta análise se presta à busca de repostas aos dilemas filosóficos e práticos do campo, como: a) estaria a formação curricular dos pesquisadores em Ciência da Informação apta para responder às demandas epistemológicas apontadas pelo pensamento informacional na atualidade?; b) as perspectivas epistemológicas anunciadas e debatidas no discurso contemporâneo do campo têm obtido aplicação diante das transformações do meio digital?; c) como fica a conceituação da Ciência da Informação diante das diferentes movimentações epistemológicas do campo? Cabe-nos, pois, um olhar filosófico, crítico e plural sobre os destinos da epistemologia do nosso fazer, à procura do esclarecimento de seus desafios éticos e sociais.

\section{A epistemologia da Ciência da Informação a caminho do humanismo...}

Um conjunto de hipóteses é observado em nosso percurso inicial, uma vez observadas as transformações discursivas nos últimos 20 anos - décadas de 1990 e atual. Partindo de um referencial panorâmico, o contexto de ascensão do pragmatismo - e, a partir dele, dos elementos identitários do enfoque humanista -, será reconhecido por Capurro como paradigma hermenêutico-retórico (1992) e paradigma social (2003), por Rendón Rojas (1996) como enforque pragmático, por Araújo (2003) como abordagens micro-sociológicas, por González de

InCID: R. Ci. Inf. e Doc., Ribeirão Preto, v. 2, n. 1, jan./jun. p. 47-67 , 2011 
Gómez (1996) como abordagem comunicacional. No âmbito destas investigações, observamos a construção em rápido desenvolvimento de um pensamento humanista dentro da Ciência da Informação, como pode ser observado no trabalho de Capurro (1992), a partir da recuperação dos pressupostos da Retórica e da Filologia, explícitos em determinados discursos, e imersos em abordagens, metodologias e práticas informacionais.

Sob a sombra da visão anterior, identificamos a presença do pragmatismo, enquanto filosofia e método, na epistemologia do campo informacional, como via que aproxima a Ciência da Informação da Retórica e da Filologia, principalmente a partir dos anos 1990 (GONZÁLEZ DE GÓMEZ, 1996; RENDÓN ROJAS, 1996). No mesmo terreno de observação, percebemos a manifestação de "reencontros" teóricos e práticos com antigos domínios dos estudos voltados para a organização dos saberes, uma vez percebido o pragmatismo intrínseco em atividades e reflexões preocupadas em representar, transmitir e preservar os saberes no passado, tomando o homem como ser histórico e a história como categoria contingencial.

\section{A epistemologia e seus contornos}

O termo epistemologia sempre levantou questionamentos em relação ao seu significado. Segundo Japiassu (1977, p. 24), etimologicamente epistemologia significa o discurso sobre a ciência. Para esse autor, em linhas gerais, falar em epistemologia é tratar do "estudo metódico e reflexivo do saber", estudo que envolve a organização, formação, desenvolvimento e funcionamento da ciência.

A epistemologia trata, desta maneira, do estudo das "possibilidades, origem, natureza e extensão do conhecimento humano" (GONZÁLEZ DE GÓMEZ, 2001, p. 6). Segundo González de Gómez (2001, p. 6), em sua primeira constituição, a epistemologia se refere a "um saber que recebe sua forma da filosofia”. A partir desta ela obtém sua legitimidade, enquanto sua materialidade é dada pela própria ciência.

Ao procurarmos o significado de epistemologia em Abbagnano (2000, p. 183), encontramos os termos gnoseologia (italiano), erkenntnistheorie (alemão), epistemology (inglês) e gnoséologie (francês). Os significantes trazem a mesma bagagem semântica daquilo que em

InCID: R. Ci. Inf. e Doc., Ribeirão Preto, v. 2, n. 1, jan./jun. p. 47-67 , 2011. 
português se denominou teoria do conhecimento. Esta última não referia-se, inicialmente, a uma disciplina filosófica, como a Lógica ou a Ética, mas "um modo de tratar um problema nascido de um pressuposto específico, no âmbito de determinada corrente filosófica”.

Para Santos (1989, p. 22) vivenciamos um outro olhar sobre as concepções de ciência e método e, deste modo, sobre a epistemologia. Para o autor, assim como para Bachelard (1968, p. 147), este olhar indica o retorno à complexidade e ao olhar historicista sobre o homem, veiculado pelo movimento humanista. No contexto epistemológico atual atravessamos um momento que recusa o cientificismo, isto é, a idéia da ciência como um saber neutro e natural, a-histórico, apolítico e soberano.

A história da ciência atravessaria, assim, um processo de "desdogmatização". Retomando diferentes domínios do humanismo, a reflexão epistemológica caminha até o encontro de seus "usuários", os indivíduos em suas comunidades (SANTOS, 1989, p. 30). Percebe-se, desta maneira, a presença de uma filosofia pragmatista dentro do pensamento epistemológico contemporâneo, fundamento que será, como visto, apropriado sob diferentes aspectos pela Ciência da Informação e que marca, filosoficamente, a construção de um ponto de vista humanista sobre as práticas da organização dos saberes.

\section{A Ciência da Informação e os estudos voltados para organização dos saberes: do pragmatismo ao humanismo...}

Segundo sua historiografia mais difundida, a Ciência da Informação, em suas bases física e cognitiva, marcadas, respectivamente, pelos trabalhos de Shannon \& Weaver e Brookes (1980), parte de uma tradição epistemológica representacionista - cujos elementos precursores estariam no contexto da Segunda Guerra Mundial. O pensamento com foco na representação, demarcado pelo positivismo deweyano e otletiano, tem origem na Lógica e caminha até os estudos de percepção mental. No entanto, os estudos de organização dos saberes movimentaram-se ao longo dos séculos por diferentes arenas. Compreendendo a construção da Ciência da Informação como um complexo de disputas políticas e batalhas simbólicas entre os campos orientados para a preservação e o acesso aos artefatos culturais, como a Biblioteconomia e a Documentação, 
percebemos que ela faz parte da trajetória das mesmas em seu pressuposto mais profundo: dar ordem aos saberes produzidos pelo homem, visando representação, transmissão e preservação de conteúdos e plataformas.

Neste olhar historiográfico, encontramos a formação da Biblioteconomia e a emancipação de uma de suas especialidades, a Bibliografia textual, como integradas aos principais domínios do pensamento humanista: o olhar retórico-filológico sobre a complexidade dos saberes, marcado pela intertextualidade e pela contextualidade - como lembra Chartier (2001), a Bibliografia, neste contexto, deixa de designar uma lista de livros para se tornar uma ciência, uma espécie de sociologia dos textos. Como aponta Foucault (2002), no século XVI o pensamento é relacional: não havia mediação do conceito, as palavras não traziam um significado exato, o que exigia, por sua vez, uma maior erudição do organizador do conhecimento. O erudito, responsável por resolver a mediação ausente dos conceitos, atuava com a construção e transmissão do saber através do comentário, da exegese. Ali, “conhecer é comentar” (MOSTAFA, 1996, p. 37).

A partir do século XVII, "a palavras e as coisas se separam, nascendo entre elas a representação" (MOSTAFA, 1996, p. 37). Segundo Mostafa (1996, p. 38), "está aberto agora o caminho para a taxionomia", para os estudos da representação do século XVIII, o "século da classificação e dos acervos". Duas orientações definiam a história epistemológica dos estudos voltados para organização dos saberes: a primeira, mais remota, de cunho erudito e bibliófilo, humanista, em geral demarcado até o século XIX - como comenta Peter Burke (2003, p. 98), entre os séculos XVI e XVII eram necessários "bibliotecários-filósofos" ou "filósofosbibliotecários" para organizar os registros do conhecimento; a outra, ligada ao aparecimento das bibliotecas públicas, relacionada a uma mudança de orientação da erudição para o serviço público, um serviço dinâmico, objetivo, mais especializado.

A linha "humanista" dos organizadores do conhecimento, bibliotecários com as mais diferentes formações, era íntima dos estudos filológicos e retóricos. Estes estudos procuravam realizar "a exegese dos textos literários documentados historicamente" - filologia primitiva -, e a recuperação de publicações de manuscritos e textos - filologia moderna/científica. Era dever fundamental atuar na "custódia e salvaguarda dos textos contra a sua destruição material", além de transmitir os "textos atinentes ao grupo social a que pertence", cuidar do "sentido que se deve InCID: R. Ci. Inf. e Doc., Ribeirão Preto, v. 2, n. 1, jan./jun. p. 47-67 , 2011. 
dar ao conteúdo do texto" e da "integração dos textos em conexões mais amplas, dentro da multiplicidade de textos". (ARAÚJO, 2001, p. 4)

Em 1992, as movimentações na epistemologia da Ciência da Informação, observadas por Capurro, chamadas pelo autor de "virada pragmática", projetavam o campo para um reencontro com a Retórica - e, de um modo geral, com o Humanismo. Este último, originado no século XIV e fragmentado ao longo dos séculos, coexistindo em diferentes saberes diante da segmentação das ciências, tem por características fundamentais a) o homem como horizonte de observação, tratado como ser histórico e contingencial, b) o conhecimento plural e anti-dogmático como caminho para uma consciência crítica. O horizonte da Ciência da Informação, nesta linha filosófica, seria a dimensão contextual que investiga as formas de comunicação dos indivíduos em comunidades específicas, comungando os múltiplos de jogos de linguagem que permitem suas trocas simbólicas. (REDÓN ROJAS, 1996; GONZÁLEZ DE GÓMEZ, 1996)

Segundo Capurro (1992), o enfoque cognitivo permanecia preocupado com a dicotomia moderna assunto/objeto, enfatizando demasiadamente o ponto de vista epistemológico interessado na relação entre o homem e o mundo - e não o homem com/no mundo -, resultado do desenvolvimento da filosofia dos estudos de referência e da teoria bibliográfica fundada no metarepresetacionismo informacional. A filosofia do pragmatismo irá na direção contrária, ou seja, a concepção pragmática do conhecimento "desloca o centro da reflexão do conhecimento feito para o conhecimento no processo de se fazer, do conhecimento para o conhecer [...]". (SANTOS, 1989, p. 49)

O pragmatismo é um movimento filosófico estruturalmente relacionado aos estudos da linguagem. Seu foco, como descreve Novellino (1996), não é a definição da verdade ou da realidade, mas a compreensão do significado dos termos em diálogos específicos. Este significado era dado pelo hábito de ação, ou crença vinculada à vivência da proposição (WITTGENSTEIN, 1979). Para Peirce (1974) o pragmatismo busca um "método" que seria capaz de determinar o sentido de um conceito, ou de um signo. Para Richard Rorty (1997, p. 17), dentre as principais características do pragmatismo está o anti-representacionismo, ou seja, a insistência na noção de que não há uma "determinidade" no estudo do conhecimento, uma das características fundamentais do pensamento humanista. No âmbito pragmatista, as sociedades, os 
textos literários, as moléculas, todas estas categorias podem ser tomadas como complexas (RORTY, 1997, p. 61-62). Se a comunidade acadêmica é percebida como um grupo de indivíduos que produz significados dentro de uma realidade social, "as oposições entre as humanidades, as artes e as ciências poderiam gradualmente desvanecer-se"; "ao invés disso, seriam pensados como denotando comunidades" (RORTY, 1997, p. 67-68). Como podemos perceber, o movimento pragmatista reilumina os valores do pensamento humanista, reaproximando sujeito e objeto, partindo de uma visão generalista e globalizante dos saberes, antevendo a revisão de práticas reflexivas do Renascimento.

Entre a Retórica e a Filologia: um itinerário metodológico para conceituar o humanismo...

Conceito híbrido e historicamente polifônico, o humanismo pode ser compreendido a partir de diferentes olhares. Segundo Abbagnano (2000, p. 602), o termo humanismo é utilizado para indicar duas instâncias diferenciadas. Em um primeiro significado, representa o movimento literário e filosófico, nascido na Itália, a partir da segunda metade do século XIV, que se espalharia para diferentes sociedades européias, definindo, a partir de seus desdobramentos, o conceito de cultura moderna que atualmente reconhecemos. Em sua segunda acepção, o termo humanismo partiria de um olhar genérico sobre o fundamentos da filosofia humanista.

Desta maneira, o conceito designaria todo movimento ou corrente de idéias que tem como fundamento a natureza humana e delimita-se a partir dos interesses do homem. Neste sentido, as bases elementares do humanismo seriam: a) reconhecimento do homem como objeto central de estudo, com a valorização da ação contra a contemplação e de todos os mecanismos capazes de dar ao homem as condições de viver uma realização plena diante da natureza; b) reconhecimento da historicidade do homem, ou seja, seu papel como agente e fruto de contingências históricas, onde a Filologia tem papel fundamental na determinação dos contextos sócio-culturais de produção do conhecimento; c) reconhecimento do valor das letras e artes clássicas, ou seja, valorização das humanidades, ou disciplinas voltadas para a formação de virtudes, e não apenas de transmissão de técnicas, onde a retórica exercerá papel fundamental, em sua construção e desconstrução dos discursos inseridos no tempo nos registros dos saberes acumulados pela Idade Média e organizados pela tradição filológica. (ABBAGNANO, 2000, p. 603)

InCID: R. Ci. Inf. e Doc., Ribeirão Preto, v. 2, n. 1, jan./jun. p. 47-67 , 2011. 
Como indica o historiador Peter Burke (2003, p. 40), o movimento humanista, que nos traria, em sua visão, os significados do conceito de humanismo, representaria um processo menos de inovação e mais de ressurgimento da cultura clássica. No entanto, este processo seria, para o historiador, um deslocamento de ruptura, ao propor um outro olhar sobre a realidade apresentada pela filosofia escolástica.

Segundo Mário Fuks (1992, p. 118), a relatividade da verdade que acompanha as ciências humanas está implícita em duas das principais áreas de estudo do humanismo no período renascentista: a Filologia e a Retórica. A Retórica repousa em uma linhagem teórica baseada na compreensão pelo diálogo. Esta disciplina era fundamental para a interpretação da realidade, constituindo um método que se sustentava na noção de que o homem é um "ser eminentemente histórico, sujeito a constantes mutações". Assim, "no terreno daquilo que é temporal e mutável, não podemos operar com ciências demonstrativas, verdadeiras e certas para qualquer época, mas pelas opiniões, retóricas, variáveis e mutáveis" (FUKS, 1992, p. 127-128).

A Filologia, por sua vez, é "o instrumento que viabiliza" o "diálogo com o passado" (FUKS, 1992, p. 119). Para o filólogo, a "história é o lugar onde se manifestam as diferenças culturais". Assim "o pragmatismo da educação humanista" visa "transformar o homem pela aquisição de virtudes", enquanto as das ciências naturais, que influenciarão os estudos da informação profundamente no século XX, "visam transformar a natureza através da aquisição de técnicas" (FUKS, 1992, p. 127). De um modo geral, a Filologia, que desenvolveu-se teoricamente até a virada do século XIX para o XX - seu ápice argumentativo -, focava-se na resistência a teorias únicas e dogmáticas e na prudência da hermenêutica, pautando-se pela cautela na determinação dos sentidos.

Retórica e Filologia, como apresenta Souza (2006), são disciplinas que se acham atualmente dispersas em um grande número de teorias, métodos e matérias de diferentes campos científicos, como a Semiótica, o Estruturalismo e a Psicanálise. São exemplos ainda as profundas manifestações da Retórica em Derrida, Foucault e Habermas, bem como da Filologia na Crítica Literária, na Biblioteconomia, na Museologia e na Etnografia. A especialização das ciências, ocorrida na virada do século XIX para o XX, é uma das justificativas para esta dispersão.

InCID: R. Ci. Inf. e Doc., Ribeirão Preto, v. 2, n. 1, jan./jun. p. 47-67 , 2011 
Na Ciência da Informação, os discursos epistemológicos que explicitam o olhar humanista têm sido presentificados através de diferentes maneiras no pensar e no fazer informacionais. $\mathrm{O}$ pragmatismo e seu foco de investigação na linguagem apresenta-se como via filosófica para esta condição. Os autores e abordagens mencionados se apresentam, do mesmo modo, como elementos que permitem o reconhecimento do humanismo no campo.

A partir destas constatações, observamos, no âmbito metodológico, o avanço das metódos qualitativos, mais atentos às narrativas. No plano teórico, notamos a intensa produção de modelos e propostas de pensamento íntimas das ciências humanas e sociais, principalmente Psicologia social, Sociologia do Conhecimento, Sociolingüística e Antropologia, foco de pensamento este que toma o conceito de contexto como fundamental para toda e qualquer investigação, permitindo, como afirma González de Gómez (1996), apreender os fenômenos e processos de informação como processos sociais, cognitivos e comunicacionais. Os conceitos de comunicabilidade e cultura tornam-se demarcações na epistemologia do campo e as pesquisas sobre ética e responsabilidade social no âmbito científico se expandem, como identificamos em Freire $(2003,2004)$.

A Ciência da Informação atravessaria assim o chamado momento semiótico, investigado por González de Gómez (1993), quando há a passagem das filosofias da consciência em direção às filosofias da linguagem - esta última, reconhecida e analisada no trabalho de Gracioso (2008). Se tomamos o vocabulário de Martínez Rider \& Rendón Rojas (2004), a epistemologia informacional estaria vivenciando o paradigma simbólico, uma resposta ao positivismo e ao representacionismo, que parte de métodos hermenêuticos e etnográficos. Este paradigma apresenta em seu modelo a observação da constituição de normas sociais e a formação de consensos locais, e aborda a realidade como um estado de categorias lingüisticamente construído. A linguagem, aqui, tem importância vital, pois é através dela que se pode conhecer o real.

Em termos de propostas teóricas, dentre as evidências mais objetivas destas movimentações na Ciência da Informação, como já mencionado, temos abordagens como a Análise do Domínio, de Hjorland \& Albrechtsen, a Antropologia da Informação, de Marteleto, a Cibersemiotica, de Brier, além da poli-representação de Ingwersen. Não por acaso, todas elas são apresentadas nos anos 1990, quando crescem as manifestações sobre a emergência de um 
pensamento humanista no desenvolvimento da ciência como um todo, demarcado pela presença de autores das ciências sociais e humanas, procurando compreender a atividade científica a partir de sua complexidade, e não de sua naturalização, mesmo período em que Capurro (1992), Rendón Rojas (1996) e González de Gómez (1996) apontam os horizontes pragmatistas da Ciência da Informação.

Manifestações da Retórica e da Filologia na Ciência da Informação: o humanismo em cena...

De um modo geral, a ascensão de um ponto de vista pragmatista dentro do campo anuncia a recuperação explícita de inúmeros elementos do pensamento humanista. As razões para esta ascensão podem ser resumidas na urgência de uma agenda de pesquisa que não negligenciasse os fatores sociais envolvidos na organização dos saberes - ou seja, a urgência de uma teoria social para as aplicações abre caminho para a discussão em torno de um pensamento que aliasse o caráter prático dos estudos informacionais e sua profunda relação com os discursos múltiplos dispersos na sociedade que afetam/recondicionam estruturalmente a informação.

Para o pragmatismo informacional, os caminhos do conhecimento de uma epistemologia para a informação são imaginados como no pensamento pragmatista de Wittgenstein (1979), ou seja, como a descrição do uso que fazemos da própria informação. Este outro olhar sobre a Ciência da Informação volta-se para o estudo do indivíduo em suas relações sócio-culturais, nas comunidades de uso e desdobramento da linguagem, ou comunidades discursivas. No bojo destas transformações percebemos

a) movimentações no conceito de Ciência da Informação: uma vasta revisão epistemológica é percebida na paisagem contemporânea de nossa epistemologia a partir da desconstrução dos discursos que "revelam" o "ser" do campo. Uma gama considerável de trabalhos traçam releituras das correntes teóricas da Ciência da Informação, discutindo seu posicionamento como ciência social, uma vez que para este ponto de vista o homem é o objeto, e não a informação - em outras palavras, temos a indicação da Ciência da Informação como ciência social (AZEVEDO NETTO, 1999; PINHEIRO, 1997; SILVA, 1999), ciência interdisciplinar (SARACEVIC, 1996; CARVALHO, 1999; PINHEIRO, 1997, 2002), ciência 
pós-moderna (WERSIG, 1993), ciência hermenêutica (CAPURRO, 1992), ciência de natureza cognitiva, nem ciência social ou humana, mas heterológica, plural e inter-relacional (LOUREIRO, 1999, p. 74), antes de uma ciência, um saber humano e social (QUEIRÓS, 1999, p. 48); ciência do paradigma emergente (SILVA, 1999, p. 79-117);

b) deslocamentos no conceito de informação: ocorre a flexibilização do termo "informação" enquanto unidade de um racionalismo cientificista. Para o pragmatismo, a informação é aquilo que cada comunidade faz agir como tal, ou seja, informação é ação e seu significado é o uso desta ação em cada contexto, em cada comunidade discursiva (HJORLAND, ALBRECHSEN, 1995), em cada cultura (MARTELETO, 2002);

c) movimentações epistemológicas para além da representação: ocorre um deslocamento que vai da unilateralidade de compreensão da linguagem como representação para a linguagem como entidade comunicacional ou "transmissionista", como observado por Novellino (1996) e González de Gómez (1996). A ação de transferência da informação engloba representação, recuperação e comunicação, desta maneira, é vislumbrada uma passagem das linguagens documentárias (representacionista) para as linguagens de transferência, pois o significado não está no texto, mas no contexto (NOVELLINO, 1996);

d) deslocamento das metodologias de investigação: como mencionado, as metodologias de investigação ganham configurações de ordem qualitativa, não identificando-se necessariamente com aquelas de ordem quantitativa. Assim, os métodos face-a-face são mais requeridos - as abordagens linguiísticas, sociológicas e antropológicas são incentivadas, somandose àquelas voltadas para a estatística de eventos sociais, e daquelas concentradas na análise comportamental dos indivíduos. Neste âmbito as unidades de análise passam a ser a palavra, a narrativa, as vozes, a historicidade, a contextualidade. Cresce, nas práticas informacionais, a adoção de metodologias como redes sociais, discurso do sujeito coletivo, grupo de foco, análise do discurso, entrevista de história de vida, observação participante, todas essas mais sensíveis à atmosfera de construção e dispersão dos jogos de linguagem.

e) movimentação dos objetos de observação: ocorre um deslocamento do objeto “capturável” informação - entidade de uma sociedade da informação - para o horizonte instável das relações sociais - entidades dispersas em comunidades específicas; o homem em sua InCID: R. Ci. Inf. e Doc., Ribeirão Preto, v. 2, n. 1, jan./jun. p. 47-67 , 2011. 
sociedade é o horizonte a ser investigado (CAPURRO, 1992). Neste aspecto, a recuperação da informação, anteriormente abordada segundo os enfoques positivistas deweyanos, otletianos e shannonianos, é revisada a partir de abordagens como a poli-representação (INGWERSEN, 1996) e a cibersemiótica (BRIER, 1996);

f) movimentação voltada para a afirmação da interdisciplinaridade da Ciência da Informação: a partir da retomada da visão de mundo relacional do pensamento humanista, compreendendo a construção da ciência segundo sua perspectiva dialógica e plural, assim como percebia a Retórica e o método filológico, diferentes trabalhos se apresentam rediscutindo a noção de natureza interdisciplinar do campo, definindo os horizontes de investigação dos estudos informacionais como orientados para um olhar múltiplo e colaborativo do processo de tecitura dos saberes globais em contextos locais. São exemplos as publicações científicas que procuram definir as relações interdisciplinares do campo, a partir do estudo das fronteiras disciplinares da Ciência da Informação. (PINHEIRO, 1998, 2005; PINHEIRO, LOUREIRO, 1995; SARACEVIC, 1996);

g) recuperação de esferas historiográficas afastadas de um discurso histórico tradicional: um conjunto de trabalhos atentando para a importância de autores e abordagens que fundamentarão o discurso historiográfico da Ciência da Informação é desenvolvido, retomando, reconhecendo, descrevendo e analisando estas obras anteriores, bem como diferentes mitos precursores do campo - como reflete Collin Burke (2007), encontramos diversos trabalhos voltados para pequenas biografias, reminiscências autobiográficas, descrições em participações de projetos e aplicações de métodos. São exemplos o reposionamento de autores como Jesse Shera e Paul Otlet na historiografia informacional, identificado em pesquisadores como Ferreira (2006), Ortega (2007), Oddone (2007), Fallis (2002) e Budd (2002), além do resgate da história de Vannevar Bush, com Harmon \& Houston (2007).

h) por fim, movimentação dos estudos de organização dos saberes científico para os estudos de organização dos saberes múltiplos: com seu anti-essencialismo e seu anti-dogmatismo, o pragmatismo expande os campos de observação da atividade científico-informacional para além dos "muros" da academia - uma Ciência da Informação para além do estudo unilateral das comunidades científicas. Trata-se do reconhecimento das linguagens primitivas produzidas por 
cada comunidade específica, dentro ou fora das sociedades científicas, ou apenas comunidades discursivas. (HJORLAND, ALBRECHTSEN, 1995)

Retomando, estes caminhos trilhados pela epistemologia do campo desvelam diferentes configurações da pesquisa em Ciência da Informação, propondo e recuperando abordagens que re-iluminam domínios do pensamento humanista. A identificação e a compreensão destes enfoques é permitida pela comparação dos elementos teóricos e metodológicos apresentados na formação discursiva epistemológica da Ciência da Informação com aqueles presentes nas duas principais disciplinas do humanismo - Retórica e Filologia.

Considerações finais: para compreender o "humanismo informacional"...

Diante do panorama apresentado, identificamos a necessidade de desenvolvimento de estudos interpretativos dos discursos que aproximam e identificam a Ciência da Informação como campo aberto e praticante das abordagens íntimas do pensamento humanista. Tendo que o pragmatismo sustenta-se diretamente como um caminho, no discurso e na prática do campo, para a compreensão da realidade científica informacional, apontamos a abordagem pragmatista de Ludwig Wittgenstein como importante elemento metodológico de compreensão desta realidade epistemológica na Ciência da Informação.

A amplitude de elementos subjetivos deste panorama revela, ainda, a complexidade do campo de análise. Diante da multiplicidade de teorias e métodos, de influências discursivas e plataformas de pesquisa do campo informacional, entendemos como fundamental abordar as comunidades científicas como formas de vida, e a produção e o entrelaçamento dos discursos, possibilitados pelos diversos mecanismos de diálogo da comunicação científica, como jogos de linguagem que constituem a gramática que rege os pesquisadores de um determinado corpo científico, em um determinado contexto histórico, e trocam semelhanças de família que permitem a identificação de comunidades de vivência. (WITTGENSTEIN, 1979)

Compreendendo a produção científica como uma construção cultural, acreditamos que as dissertações, teses e artigos e seu dinâmica de inter-citações são conjuntos de jogos de linguagem que constituem micro-formas de vida, trocando familiaridades. Assim, para reconhecer a InCID: R. Ci. Inf. e Doc., Ribeirão Preto, v. 2, n. 1, jan./jun. p. 47-67 , 2011. 
gramática de uma forma de vida - aqui focada em uma espécie de "humanismo informacional" na epistemologia contemporânea da Ciência da Informação, podemos, nestes veículos, explorar os indícios do olhar humanista, tendo a conceituação das disciplinas Retórica e Filologia como elementos de aproximação comparativa.

A unidade gramatical dos estudos pragmatistas da informação gira em torno da análise da forma como determinadas comunidades constroem, a partir das linguagens que comungam, suas apropriações sobre a informação. A comunidade discursiva específica, reconhecida em sua cultura, é o objeto de estudo; para penetrá-lo, é necessário, preliminarmente, conhecer e conviver com seus jogos de linguagem - ou critérios com os quais constroem e compartilham seus saberes -, a partir da investigação dos usos que este grupo de indivíduos confere aos signos com os quais se comunica - os discursos - como ponto de partida da análise.

\section{Referências}

ABBAGNANO, N. Dicionário de filosofia. São Paulo: Martins Fontes, 2000.

AZEVEDO NETTO, C. X. de. Uma face da Ciência da Informação. In: PINHEIRO, L. V.R. Ciência da informação, ciências sociais e interdisciplinaridade. Brasília; Rio de Janeiro: IBICT/DDI/DEP, 1999. p. 133-141

ARAÚJO, J. I. de. Filologia românica. Viçosa: Universidade Federal de Viçosa, 2001.

ARAÚJO, C. A. A. A ciência da informação como ciência social. Ciência da Informação, Brasília, v. 32, n. 3, Brasília, set./dez. 2003.

BACHELARD, G. O novo espírito científico. Rio de Janeiro: Tempo Brasileiro, 1968.

BRIER, S. Cybersemiotics: a new interdisciplinary development applied to the problems of knowledge organization and document retrieval in information science. Journal of Documentation, v. 52, n. 3, p. 296-344, sep. 1996.

BROOKES, B. C. The foundations of information science: Part I. Philosophical aspects. Journal of Information Science principles and practice, v. 2, p. 125-133, 1980.

BUDD, J. M. Jesse Shera, social epistemology and praxis. Epist. social, v. 16, n. 1, p. 93-98, 2002. 
BURKE, C. History of information science. Annual Review of Information Science and Technology, v. 41, p. 3-53, 2007.

Uma história social do conhecimento. Rio de Janeiro: Jorge Zahar, 2003.

CAPURRO, R. What is Information Science for? a philosophical reflection. In: VAKKARI, P.; CRONIN, B. (Eds.). Conceptions of Library and Information Science; historical, empirical and theoretical perspectives. London, Los Angeles: Taylor Graham, 1992. p.82-96.

Epistemologia y ciencia de la información. In: ENCONTRO NACIONAL DE PESQUISA EM CIÊNCIA DA INFORMAÇÃO, 5, 2003, Belo Horizonte. Anais... Belo Horizonte, Escola de Ciência da Informação da UFMG, 2003.

CARVALHO, E. C. A natureza social da Ciência da Informação. In: PINHEIRO, Leda Vânia R. Ciência da informação, ciências sociais e interdisciplinaridade. Brasília; Rio de Janeiro: IBICT/DDI/DEP, 1999. p. 51-63

CHARTIER, R. Uma crise da história? A história entre a narração e o conhecimento. In: PESAVENTO, S. J. Fronteiras do milênio. Porto Alegre: UFRGS, 2001. p. 115-140.

DAY, R. Poststructuralism and information studies. Annual review of information scicence social and technology (ARIST), v. 39, p. 575-609, 2005.

FERREIRA JR., H. da S. Otlet realizador ou visionário? O que existe em um nome? Ciência da Informação, Brasília, v. 35, n. 2, p. 9-16, maio/ago. 2006. Disponível em: $<w w w . s c i e l o . b r / p d f / c i / v 35 n 2 / a 02 v 35 n 2 . p d f>$. Acesso em: 23/08/07

FALLIS, D. Introduction: social epistemology and information science. Social Epistemology, v. 16, n. 1, p. 1-4, 2002.

FOUCAULT, M. As palavras e as coisas: uma arqueologia das ciências humanas. 8. ed. São Paulo: Martins Fontes, 2002. (Coleção Trópicos).

FREIRE, I. M. O olhar da consciência possível sobre o campo científico. Ciência da Informação, Brasília, v. 32, n. 1, p. 50-59, jan./abr. 2003.

A responsabilidade social da Ciência da Informação na perspectiva da consciência possível. DataGramaZero - Revista de Ciência da Informação, v. 5, n. 1, fev. 2004. Disponível em: <http://www.dgz.org.br/> Acesso em: 18/04/07.

FUKS, M. Considerações a respeito do lugar das humanidades na história da ciência moderna. Dados - revista de ciências sociais, Rio de Janeiro, v. 35, n. 1, p. 117-135, 1992.

GOMES, M. Y. F. S. de. Dissertações defendidas no Programa de Pós-Graduação em Ciência da Informação da UFMG, na década de 1990: um balanço. Perspectivas em Ciência da Informação, Belo Horizonte, v. 11, n. 3, p. 318-334, set./dez. 2006. 
GONZÁLEZ DE GÓMEZ, M. N. A representação do conhecimento e o conhecimento da representação: algumas questões epistemológicas. Ciência da Informação, Brasília, v. 22, n. 3, p. 217-222, set./dez. 1993.

Comentários ao artigo "Hacia um nuevo pardigma em bibliotecologia".

Transinformação, Campinas, v. 8, n. 3, p. 44-56, set./dez. 1996;

Para uma reflexão epistemológica acerca da Ciência da Informação. Perspectivas em Ciência da Infoemação, Belo Horizonte, v. 6, n. 1, p. 5-18, jan./jun. 2001.

GRACIOSO, L. de S. Filosofia da linguagem e Ciência da Informação: jogos de linguagem e ação comunicativa no contexto das ações de informação em tecnologias virtuais. 2008. 180 f. Tese (Doutorado) - Instituto Brasileiro de Informação em Ciência e Tecnologia, Universidade Federal Fluminense, Rio de Janeiro, 2008.

HJORLAND, B.; ALBRECHTSEN, H. Toward a new horizont in information science: domainanalysis. Journal of the American Society for Information Science, v. 46, n. 6, p. 400-425, jul. 1995.

HOUSTON, R.; HARMON, G. Vannevar Bush and Memex. Annual Review of Information Science and Technology, v. 41, p. 55-92, 2007.

INGWERSEN, P. Cognitive perspectives of information retrieval inferaction: elements of a cognitive IR theory. Journal of Documentation, v. 52, n. 1, p. 3-50, march. 1996.

JAPIASSU, H. Introdução ao pensamento epistemológico. Rio de Janeiro: Francisco Alves, 1977.

LOUREIRO, J. M. M. Ciência da informação: nem ciência social nem humana, apenas uma ciência diferente. In: PINHEIRO, L. V. P. Ciência da informação, ciências sociais e interdisciplinaridade. Brasília; Rio de Janeiro: IBICT/DDI/DEP, 1999. p. 65-77.

MARTELETO, R.M. Conhecimento e sociedade: pressupostos da Antropologia da Informação. In: AQUINO, M. de A. (org.). O campo da Ciência da Informação: gênese, conexões e especificidades. João Pessoa: Universitária, 2002. p. 101 - 115.

MARTÍNEZ R. R. M.; RENDÓN ROJAS, M. Á. Algunas propuestas latinoamericanas de objetos de estudio para la investigácion bibliotecologica. Rev. Interam. Bibliot., Medellín, v. 27, n. 1, enero-junio, 2004.

MOSTAFA, S. P. Filosofando sobre a área de informação. In: SIMPÓSIO BRASIL-SUL DE INFORMAÇÃO: assumindo um novo paradigma acervo versus informação, 1996, Londrina. Anais... Londrina : UEL, 1996. v. 1. p. 31-45. 
NOVELLINO, M.S.F. A teoria da ação comunicativa e a representação da informação. Informare: cadernos do programa de pós-graduação em Ciência da Informação, Rio de Janeiro, v. 2, n. 2, p. 73-79, jul./dez. 1996.

ODDONE, N. Revisitando a "epistemologia social": esboço de uma ecologia sociotécnica do trabalho intelectual. Ciência da Informação, Brasília, v. 36, n. 1, p. 108-123, jan./abr. 2007.

ORTEGA, C. D. A documentação como origem e base fértil para a ciência da informação. In: ENANCIB - Enc. Nacional de Pesquisa em Ciência da Informação, 8, 2007, Salvador. Comunicações de pesquisas do GT1. Salvador: UFBA, 2007.

PEIRCE, C. S. Conferências sobre o pragmatismo. In: CHARLES SANDERS PEIRCE; GOTTLOB FREGE. São Paulo: Abril Cultural, 1974. (Os pensadores, 36) p. 11-66.

PINHEIRO, L.V. R.; LOUREIRO, J. M. M. Traçados e limites da ciência da informação. Ciência da Informação, Brasília, v. 24, n. 1, p. 42-53, jan./abr. 1995.

PINHEIRO, L.V.R. A Ciência da Informação entre sombra e luz: domínio epistemológico e campo interdisciplinar. 1997. 278 p. Tese (doutorado) - Universidade Federal do Rio de Janeiro. Rio de Janeiro, 1997.

Campo interdisciplinar da ciência da informação: fronterias remotas e recentes. Investigação Bibliotecologica, v. 12, n. 25, p. 132-163, dez. 1998;

. Gênese da Ciência da Informação ou sinais anunciadores da nova área. In: AQUINO, Mirian de Albuquerque (org.). O campo da ciência da informação: gênese, conexões e especificidades. João Pessoa: Ed. Universitária, 2002. p. 61-86

Processo evolutivo e tendências contemporâneas da ciência da informação. Informação e Sociedade, João Pessoa, v. 15, n. 1, 2005. Disponível em: <http://periodicos.ufpb.br/ojs2/index.php/ies/article/view/51>. Acesso: 15 maio 2007.

QUEIRÓS, C. F. G. G. de. É a ciência da informação um saber humano ou social? In: PINHEIRO, Lena Vânia Ribeiro. Ciência da informação, ciências sociais e interdisciplinaridade. Brasília; Rio de Janeiro: IBICT/DDI/DEP, 1999.

RENDÓN ROJAS, M. A. Hacia um nuevo paradigma em bibliotecologia. Transinformação, Campinas, v. 8, n. 3, p. 17-31, set./dez. 1996.

RORTY, R. Objetivismo, relativismo e verdade. Rio de Janeiro: Relume-Dumará, 1997.

SANTOS, B. Um discurso sobre as ciências. 9. ed. Porto: edições Afrontamento, 1987.

SANTOS, B. Introdução a uma ciência pós-moderna. 3. ed. Rio de Janeiro: Graal, 1989. 
SARACEVIC, T. Ciência da Informação: origem, evolução, relações. Perspectivas em Ciência da Informação, Belo Horizonte, v. 1, n. 1, p. 41-62, jan./jun. 1996.

SILVA, J.G. e. Ciência da informação: uma ciência do paradigma emergente. In: PINHEIRO, Lena Vânia Ribeiro. Ciência da informação, ciências sociais e interdisciplinaridade. Brasília; Rio de Janeiro: IBICT/DDI/DEP, 1999. p. 79-117

SOUZA, R.A. de. Iniciação aos estudos literários: objetos, disciplinas, instrumentos. São Paulo: Martins Fontes, 2006. (Biblioteca Universal).

WERSIG, G. Information science: the study of postmodern knowledge usage. Information processing and management, v. 29, n. 2, p. 229-239, 1993

WITTGENSTEIN, L. Investigações filosóficas. 2. ed. São Paulo: Abril Cultural, 1979. 